\title{
High Incidence of Thrombotic Thrombocytopenic Purpura Exacerbation Rate Among Patients With Morbid Obesity and Drug Abuse
}

Preethi Ramachandran ${ }^{1}$, Burak Erdinc ${ }^{2}$, Hesham Ali Abowali ${ }^{2}$, Umar Zahid ${ }^{3}$, Vladimir Gotlieb ${ }^{1}$, Samuel Spitalewitz ${ }^{3}$

1. Hematology and Oncology, Brookdale University Hospital Medical Center, Brooklyn, USA 2. Internal Medicine, Brookdale University Hospital Medical Center, Brooklyn, USA 3. Nephrology, Brookdale University Hospital Medical Center, Brooklyn, USA

Corresponding author: Burak Erdinc, berdinc@icloud.com

\begin{abstract}
This study aims to identify the baseline patient characteristics, clinical presentation, and response to treatment of 11 patients who were diagnosed with thrombotic thrombocytopenic purpura (TTP) between 2014 and 2020 at Brookdale University Hospital Medical Center, Brooklyn, NY. Laboratory and clinical parameters were recorded for 29 patients who received plasmapheresis in this time period. Of 29 patients, 11 had confirmed TTP and one was diagnosed with hereditary TTP. Young, black, and female patients made up the majority of our patient population. A high prevalence of obesity and drug abuse were seen among our patients. Five out of 11 were obese and four of them were morbidly obese; six out of 11 patients were positive for the drug screen including cannabinoids (3), opiates (2), benzodiazepines (1), PCP (1), and methadone (1). Four patients with a positive drug screen had acute kidney injury (AKI), and plasmapheresis helped them enhance their kidney function. We observed a high incidence of AKI and high TTP exacerbation rates in patients who were drug abusers and those who were morbidly obese. There is a paucity of data on the relationship of TTP with obesity or drug abuse and this needs further study.
\end{abstract}

Categories: Internal Medicine, Nephrology, Hematology

Keywords: thrombotic thrombocytopenic purpura, african american, obesity, drug abuse

\section{Introduction}

Thrombotic thrombocytopenic purpura (TTP) is a rare disease with high mortality affecting two people per million per year. It is characterized by thrombotic microangiopathy secondary to thrombocyte aggregation caused by a disintegrin and metalloprotease with thrombospondin type 1 repeats, member 13 (ADAMTS13) deficiency [1,2]. ADAMTS13 deficiency can be acquired or congenital. Acquired TTP is primarily caused by autoantibodies leading to the accumulation of large von Willebrand factor (vWF) multimers causing platelet aggregation and microangiopathic hemolytic anemia (MAHA). TTP classically presents as a pentad: thrombocytopenia, MAHA, kidney injury, neurological involvement, and fever. Even though the "classic pentad" is described to help with the diagnosis of the disease, it is neither sensitive nor specific as in our study. Therefore, the lack of a full pentad should not be used to exclude the diagnosis. Replenishing

\section{Materials And Methods}

This study was approved by the Research and Clinical Projects Committee (IRB) of Brookdale University Hospital and Medical Center (BUHMC) on April 28, 2020. A chart review was performed on 29 patients who received plasmapheresis at Brookdale University Hospital and Medical Center in Brooklyn, New York, between 2014 and 2020.

\section{Subjects}

Our study included 11 patients with the correct diagnosis of TTP. Diagnostic criteria included (1) clinical manifestations characterized by thrombocytopenia, microangiopathic hemolytic anemia (MAHA) and/or neurological manifestations, fever, acute kidney injury; (2) laboratory investigations included hemolytic anemia, thrombocytopenia, elevated lactate dehydrogenase level (LDH), schistocytes on peripheral smear, negative Coomb's test, normal prothrombin time (PT) and partial thromboplastin time (PTT); (3) significantly decreased ADAMTS13 activity (<10\%); and (4) exclusion of hemolytic uremic syndrome (HUS), disseminated intravascular coagulation (DIC) and other causes of thrombotic microangiopathies (TMA), such as HELLP syndrome, Evans syndrome, and eclampsia.

\section{Clinical data}


Clinical data of our cases were collected from HYPERSPACE® Epic 2019 Aug, electronic medical record system by reviewing their demographics, medical history, home medications, presenting symptoms, comorbidities, laboratory parameters, ADAMTS13 level, and treatments received. Clinical features included thrombocytopenia with microangiopathic hemolytic anemia, the presence of acute kidney injury, fever, and neurological symptoms. Laboratory parameters included initial hemoglobin, lowest hemoglobin, reticulocyte count, initial platelet count, lowest platelet count, lactate, lactate dehydrogenase (LDH), serum creatinine on admission, baseline creatinine, alanine aminotransferase (ALT), aspartate transaminase (AST), initial and peak troponin, presence of antinuclear antibody (ANA), ADAMTS13 level and ADAMTS13 inhibitor level.

\section{Measurements of ADAMTS13 activity and antibodies to ADAMTS13}

Blood samples to measure ADAMTS13 activity and inhibitor level were collected from the patients before the plasma exchange. ADAMTS13 activity was measured by Quest Diagnostics Nichols Institute, Chantilly, VA, using a chromogenic, enzyme-linked immunosorbent assay (ELISA). Inhibitor testing was performed when ADAMTS13 activity levels are equal to or less than $30 \%$. The patient's sample is heat-inactivated and mixed with an equal volume of pooled normal plasma (PNP) before testing. After testing, the residual activity is calculated, and the inhibitor concentration is expressed in Bethesda equivalent units (BEU).

\section{Assessment of therapeutic effects}

Complete remission was defined as full clinical recovery and recovery of a normal platelet count (>150 $\mathrm{x}$ $10^{9} / \mathrm{L}$ ) for at least two days. Exacerbation was defined as a recurrent disease within 30 days after reaching a treatment response. Relapse was defined as recurrent disease 30 days or longer after reaching a treatment response.

\section{Statistical analysis}

Mortality, exacerbation, and relapse rate were described using descriptive statistics. We used median and interquartile range (IQR) as data were not normally distributed. Categorical variables were presented as frequency and percentages. The mean of continuous variables was compared using the Mann-Whitney U test, while for categorical variables Fischer's exact test was performed as of small data size.

\section{Results}

Eleven patients were diagnosed with TTP (thrombotic thrombocytopenic purpura) at Brookdale University Hospital and Medical Center (BUHMC) between 2014 and 2020. One of the 11 patients had a hereditary form of TTP whereas the rest had acquired TTP. Nine of the 10 patients with TTP were newly diagnosed, and one had relapsed TTP. The median age was 44 years and there was a slight female predominance (64\%). The majority of our patients were African Americans (72\%) as reflective of our general patient population at BUHMC. Five of 11 patients were obese (BMI $>30 \mathrm{~kg} / \mathrm{m}^{2}$ ) and four of them were morbidly obese (BMI $>40$ $\mathrm{kg} / \mathrm{m}^{2}$ ). Three patients had autoimmune disorders at the time of diagnosis (two patients with Hashimoto's thyroiditis and one with antiphospholipid syndrome). Six patients had positive drug screens which included cannabinoids (3), opiates (2), benzodiazepines (1), phencyclidine (PCP, 1), and methadone (1). Only one patient had a history of cancer (cervical cancer in remission). Five of the 11 patients had a history of prior surgeries. The main characteristics of the patients are summarized in Table 1 . The presenting symptoms on admission were gastrointestinal (63\%) neurological (54\%), cardiopulmonary (18\%) which all are summarized in Table 2. 


\section{Cureus}

Main characteristics of the patients

Age, median (range)

44 yrs (22-79 yrs)

Gender

Male

$\%$

Female

36.36

Body mass index (BMI), mean \pm SD (range)

7

63.63

Ethnicity

African American

Hispanic

$35.72 \pm 13.67(21.7-59.10)$

Asian

History of cancer

n $\%$

History of autoimmune disease

8

72.72

2

18.18

Hashimoto thyroiditis

Anti-phospholipid syndrome

Drug abuse

9.09

9.09

3

27.27

2

18.18

9.09

Cannabinoids

54.54

Opiates

27.27

Benzodiazepines

PCP

Methadone

1

18.18

9.09

9.09

9.09

\section{TABLE 1: Main characteristics of the patients}

SD: standard deviation, PCP: phencyclidine 


\section{Cureus}

\begin{tabular}{|c|c|c|}
\hline & $\mathbf{n}$ & $\%$ \\
\hline TTP pentad & 1 & 9.09 \\
\hline Microangiopathic hemolytic anemia & 11 & 100 \\
\hline Thrombocytopenia & 11 & 100 \\
\hline Renal involvement & 7 & 63.63 \\
\hline Neurological involvement & 6 & 54.54 \\
\hline Subdural hematoma & 1 & 9.09 \\
\hline Acute ischemic stroke & 1 & 9.09 \\
\hline Fever & 1 & 9.09 \\
\hline Neurological symptoms & 6 & 54.54 \\
\hline Dizziness & 4 & 36.36 \\
\hline Altered mental status & 4 & 36.36 \\
\hline Headache & 3 & 27.27 \\
\hline Syncope & 2 & 18.18 \\
\hline Seizures & 1 & 9.09 \\
\hline Focal neurologic deficits & 1 & 9.09 \\
\hline Cardiopulmonary symptoms & 2 & 18.18 \\
\hline Chest pain & 2 & 18.18 \\
\hline Shortness of breath & 1 & 9.09 \\
\hline Gastrointestinal symptoms & 7 & 63.63 \\
\hline Nausea or vomiting & 5 & 45.45 \\
\hline Abdominal pain & 4 & 36.36 \\
\hline Loss of appetite & 2 & 18.18 \\
\hline Difficulty swallowing & 1 & 9.09 \\
\hline Diarrhea & 1 & 9.09 \\
\hline Hematemesis & 1 & 9.09 \\
\hline Other symptoms & 2 & 18.18 \\
\hline Easy bruising & 1 & 9.09 \\
\hline Hematuria & 1 & 9.09 \\
\hline Dysuria & 1 & 9.09 \\
\hline
\end{tabular}

\section{TABLE 2: Initial presentation}

TTP: thrombotic thrombocytopenic purpura

Classical pentad of TTP was present in only $9 \%$ of our patients. A combination of microangiopathic hemolytic anemia and thrombocytopenia was observed in $100 \%$ of the patients. A total of $63 \%$ of patients had acute kidney injury, 54.5\% had neurological symptoms, and only $9 \%$ had fever on admission. Subdural hematoma and acute ischemic stroke were diagnosed in two of the patients who presented with neurological symptoms (Table 2). AKI was observed in four out of six patients with a positive drug screen and one of those was morbidly obese. All patients with drug abuse and AKI had a complete recovery of their renal function after TTP treatment whereas one patient had only partial improvement due to chronic kidney disease at baseline. 


\section{Cureus}

All patients had low ADAMTS13 activity of $<10 \%$. Ten of the 11 patients had high ADAMTS13 inhibitor levels and one had an undetectable level of inhibitor as the patient had hereditary TTP. The average PLASMIC score was calculated as six [4]. Mean admission hemoglobin was $9.17 \mathrm{~g} / \mathrm{dl}$ (standard deviation \{SD 2.57 ) and the lowest hemoglobin was $6.46 \mathrm{~g} / \mathrm{dl}$ (SD 1.3). Mean values of other laboratory parameters included reticulocyte count of $0.148 \times 10^{6} / \mathrm{uL}$ (SD 0.10), initial platelet count of $20.72 \times 10^{3} / \mathrm{uL}$ (SD 13.34), lowest platelet count of $10.45 \times 10^{3} / \mathrm{uL}$ (SD 6.05), lactic acid of $3.44 \mathrm{mmol} / \mathrm{L}$ (SD 2.43), lactate dehydrogenase (LDH) of $4378 \mathrm{IU} / \mathrm{L}$ (SD 2678), creatinine of $1.63 \mathrm{mg} / \mathrm{dl}$ (SD 1.03), alanine transaminase (ALT) of $42.18 \mathrm{U} / \mathrm{L}$ (SD 40.6), aspartate transaminase (AST) of $85.76 \mathrm{U} / \mathrm{L}$ (SD 51.48), initial troponin level of $0.282 \mathrm{mg} / \mathrm{ml}$ (SD 0.48), and peak troponin of $2.43 \mathrm{ng} / \mathrm{ml}$ (SD 2.91). Laboratory results are summarized in Table 3.

\begin{tabular}{|c|c|c|}
\hline & Mean \pm SD (range) & Reference range \\
\hline Initial hemoglobin & $9.17 \pm 2.57(5.7-14.8)$ & \multirow{2}{*}{$12.9-16.7 \mathrm{~g} / \mathrm{dl}$} \\
\hline Lowest hemoglobin & $6.46 \pm 1.30(5.3-8.8)$ & \\
\hline Reticulocyte count & $0.148 \pm 0.10(0.017-0.351)$ & $0.022-0.09010^{6} / \mathrm{ul}$ \\
\hline Initial platelet count & $20.72 \pm 13.34(9-52)$ & \multirow{2}{*}{$153-32810^{3} / \mathrm{ul}$} \\
\hline Lowest platelet count & $10.45 \pm 6.05(6-28)$ & \\
\hline Lactate & $3.44 \pm 2.43(1.2-10.3)$ & $0.70-2.10 \mathrm{mmol} / \mathrm{l}$ \\
\hline LDH & $4378 \pm 2678(9700-1440)$ & 313-618 IU// \\
\hline Creatinine & $1.63 \pm 1.03(0.95-4.7)$ & $0.66-1.25 \mathrm{mg} / \mathrm{dl}$ \\
\hline Alanine aminotransferase (ALT) & $42.18 \pm 40.60(11-155)$ & $21-72 \mathrm{U} / \mathrm{I}$ \\
\hline Aspartate aminotransferase (AST) & $85.76 \pm 51.48(28-194)$ & 17-59 U/I \\
\hline Initial troponin I & $0.282 \pm 0.48(0.017-1.570)$ & \multirow{2}{*}{$0.000-0.034 \mathrm{ng} / \mathrm{ml}$} \\
\hline Peak troponin I & $2.43 \pm 2.91(0.015-8.140)$ & \\
\hline \multicolumn{3}{|l|}{ ADAMTS13 activity } \\
\hline$<3 \%$ & 10 & \multirow{3}{*}{ 68-163\% activity } \\
\hline $4 \%$ & 1 & \\
\hline $14 \%$ & 1 & \\
\hline Inhibitor level & $4.94 \pm 4.69(0.7-6.7)$ & $<0.4 \mathrm{BEU}$ \\
\hline
\end{tabular}

\section{TABLE 3: Laboratory results}

SD: standard deviation, LDH: lactate dehydrogenase, ADAMTS13: a disintegrin and metalloproteinase with a thrombospondin type 1 motif, member 13, BEU: Bethesda equivalent units

All patients with an acquired form of TTP were treated with steroids and plasma exchange. In addition, three of them received immunosuppressive treatment with cyclophosphamide (2) and vincristine (1). One patient with the hereditary form of TTP received treatment with plasma infusions rather than plasma exchange. Three patients had a complicated course with systemic infections: cytomegalovirus bacteremia (1), Proteus mirabilis bacteremia (1), and group B streptococci bacteremia (1). On average, patients received 15 sessions of plasma exchange. Seventy percent of acquired TTP patients received rituximab treatment (4.5 doses on average). Complete remission was observed in $80 \%$ of our patients (days to remission: 10.5 days, SD 3.93). But unfortunately, an exacerbation was seen in $70 \%$ of the acquired TTP patients. Exacerbation rates were higher in patients with drug abuse as well as in those who were morbidly obese (Table 4). One patient was resistant to plasmapheresis and needed 60 sessions of plasmapheresis in a total of 96 days. Only one out of nine newly diagnosed acquired TTP had relapsed disease (time to relapse: three years). The length of stay was 15 days on average. All patients were discharged home after the initial diagnosis. Three patients died in three, 19, and 23 months after the initial diagnosis. 


\section{Cureus}

\begin{tabular}{|c|c|c|c|c|}
\hline & $\begin{array}{l}\text { All patients with } \\
\text { acquired TTP }\end{array}$ & $\begin{array}{l}\text { Patients with renal } \\
\text { involvement }\end{array}$ & $\begin{array}{l}\text { Patients with morbid obesity } \\
\text { (BMl>40 kg/m²) }\end{array}$ & $\begin{array}{l}\text { Patients with a history of drug } \\
\text { abuse }\end{array}$ \\
\hline Total, $\mathrm{n}$ & 10 & 7 & 4 & 5 \\
\hline $\begin{array}{l}\text { Exacerbation, } \\
\%\end{array}$ & 70.0 & 57 & 75 & 80.0 \\
\hline Relapse, \% & 20.0 & 14 & 50.0 & 40.0 \\
\hline
\end{tabular}

TABLE 4: Comparison of exacerbation and relapse rates between subgroups

TTP: thrombotic thrombocytopenic purpura

\section{Discussion}

TTP can be divided into two categories (1) more commonly seen acquired or autoimmune form (94.5\% of cases) and (2) very rare hereditary form (4.5\% of cases) caused by ADAMTS13 bi-allelic gene mutations also known as Upshaw-Schulman syndrome [5,6]. Severely decreased activity of ADAMTS13, which is primarily synthesized by stellate cells in the liver, is the cause of TTP [7,8]. ADAMTS13 activity levels less than $10 \%$ along with clinical features of the disease and laboratory findings are used to make a definitive diagnosis. The main reason for ADAMTS13 deficiency is acquired autoantibodies causing TTP but there may be additional causes that lower the ADAMTS13 levels, such as sepsis, cardiac surgery, pancreatitis, and liver disease [9-13]. An inhibitory antibody is detected in the majority of the cases [7,14].

TTP typically affects adult populations in their fourth decade of life, and is reported to be more common in young females, African Americans, and patients with a history of autoimmune disease [15]. Our patient population had 63\% females, 72\% African Americans, and 27\% with previously diagnosed autoimmune conditions. The median age in our patient population was 44 years. African American population was the highest among our patient population (73\%) compared to Oklahoma (36\%) and Harvard registry (20\%), respectively [2,16]. This can be explained by the fact that most of our patients in the community we serve are African Americans. Although active cancer and cancer-related chemotherapy have been associated with TTP, one of our patients had a history of cervical cancer that was in remission. Comparison of Harvard and Oklahoma registries with our study is summarized in Table 5. 


\section{Cureus}

\begin{tabular}{|c|c|c|c|}
\hline & Brookdale registry & Oklahoma registry [2] & Harvard registry [16] \\
\hline Geographic region & New York & Oklahoma & Massachusetts \\
\hline Number of patients & 11 & 78 & 68 \\
\hline Study population & $\begin{array}{l}\text { Clinically suspected cases of TTP } \\
\text { with severe ADAMTS13 deficiency }\end{array}$ & $\begin{array}{l}\text { Patients with the first episode of clinically } \\
\text { suspected TTP were referred for PEX. }\end{array}$ & $\begin{array}{l}\text { Clinically suspected cases of TTP } \\
\text { with severe ADAMTS13 deficiency }\end{array}$ \\
\hline $\begin{array}{l}\text { Threshold for severe } \\
\text { ADAMTS13 deficiency }\end{array}$ & $<10 \%$ & $<10 \%$ & $<10 \%$ \\
\hline Female, \% & 63.63 & 77 & 73.5 \\
\hline $\begin{array}{l}\text { Median age at Initial } \\
\text { presentation }\end{array}$ & 44 & 41 & 40 \\
\hline Ethnic groups & $\begin{array}{l}\text { Black, } 72.72 \% \text {; Hispanic, } 18.18 \% \text {; } \\
\text { Asian, } 9.09 \%\end{array}$ & $\begin{array}{l}\text { White, } 62 \% \text {; Black, } 36 \% \text {; Native American, } \\
2 \%\end{array}$ & $\begin{array}{l}\text { White, } 63.6 \% \text {; Black, } 19.7 \% \text {; Asian, } \\
1.5 \% \text { Hispanic, } 15.2 \%\end{array}$ \\
\hline \multicolumn{4}{|l|}{ Clinical findings } \\
\hline $\begin{array}{l}\text { Neurological } \\
\text { involvement, \% }\end{array}$ & 54.54 & 67 & 39.7 \\
\hline Renal involvement, \% & 63.63 & 52.5 & - \\
\hline Fever, \% & $9.09 \%$ & 10.0 & 35.3 \\
\hline \multicolumn{4}{|l|}{ Laboratory findings } \\
\hline Hematocrit, \% & $27.51(17.1-44.4)$ & $22(13-28)$ & $27(23-31)$ \\
\hline $\begin{array}{l}\text { Platelet count, } 9 \times \\
10^{9} / \mathrm{L}\end{array}$ & $20.72(9-52)$ & $11(5-63)$ & $17(12-23)$ \\
\hline $\begin{array}{l}\text { Serum creatinine, } \\
\mathrm{mmol} / \mathrm{L}\end{array}$ & $1.63(0.95-4.7)$ & $1.35(0.8-5.5)$ & $1.08(0.78-1.47)$ \\
\hline $\begin{array}{l}\text { Lactate } \\
\text { dehydrogenase, IU/L }\end{array}$ & $4378(9700-1440)$ & 1500 (274-3909) & 1107 (797-1349) \\
\hline Inhibitor positive, \% & 90.0 & 88 & 56 \\
\hline Exacerbation, \% & 70.0 & 55 & - \\
\hline Relapse, \% & 20.0 & 44 & - \\
\hline
\end{tabular}

\section{TABLE 5: Comparison of Harvard and Oklahoma registries with our study (Brookdale registry)}

TTP: thrombotic thrombocytopenic purpura, ADAMTS13: a disintegrin and metalloproteinase with a thrombospondin type 1 motif, member 13, PEX: plasma exchange

TTP causes widespread thrombosis affecting different organ systems, and some are more commonly affected than others [17]. GI symptoms tend to be commonly seen in patients with TTP ranging from $35 \%$ to $40 \%$ [18]. The range of the GI symptoms in our population was very broad from more commonly seen abdominal pain, nausea, vomiting, and diarrhea to less commonly seen symptoms like dysphagia or hematemesis. GI symptoms in our study population were observed in $64 \%$ of the patients which is slightly higher than previously reported studies. The nervous system has been reported to be the most commonly affected visceral organ at presentation, occurring in $67 \%$ of cases [2]. The symptoms might be minor such as headache or transient altered mental status (26\%) to severe such as focal neurological deficits, seizures, or coma (41\%) [2]. In our study, $54 \%$ of the patients presented with neurological symptoms ranging from mild to severe (Table 2). Moreover, two patients who presented with severe neurological symptoms such as syncope, focal neurological deficits, and seizures were diagnosed with a subdural hematoma and acute ischemic stroke. The incidence of neurological manifestations was noted to be $39.7 \%$ in the Harvard registry and $67 \%$ in the Oklahoma registry $[2,16]$. Renal dysfunction is frequently seen in patients with TTP, more commonly reported in older patients $[2,19]$. Acute kidney injury was seen in $63 \%$ of our patients, which is slightly higher than patients in the Oklahoma registry (52.5\%) [2]. Our patient population had a higher incidence of AKI than neurological symptoms compared with other registries which had a higher incidence of neurological manifestations rather than AKI. A detailed analysis into the subgroup of patients with AKI 
revealed that $57 \%$ of them had a positive drug screen and $28 \%$ of them had morbid obesity. We observed that the renal functions in most drug abusers (five of six) completely reversed back to normal within one to two weeks after treatment of TTP. Even though baseline renal functions were not available for many of these patients, the observation of improvement of renal function with TTP treatment proves the fact that substance abuse did not play a confounding role in renal impairment. Fever was noted to be common in the Harvard registry, including $35 \%$ of their patients [16]. Despite fever being one of the criteria in the classic pentad of TTP, it was rarely seen in our patient population (one of 11 patients). Even though cardiopulmonary symptoms were relatively uncommon, we had two patients (18\%) who presented with chest pain and shortness of breath. In addition, we found significantly elevated mean troponin I of 0.282 $\mathrm{ng} / \mathrm{ml}$ on admission and mean peak troponin I of $2.43 \mathrm{ng} / \mathrm{ml}$ (Table 3). Elevated troponin level is associated with a worse prognosis, as reported by Alwan F. et al in 68\% of their patients [20].

The mean hemoglobin, hematocrit, and platelet count in our study group was similar to those reported in other registries except for mean creatinine and LDH levels which were higher in our study population as illustrated in Table 5. Complete remission of TTP was observed in $80 \%$ of our patients suggesting a good response to initial therapy (days to remission: 10.5, SD 3.93). However, we found a very high rate of exacerbations (70\%) compared to previous TTP studies including the Oklahoma registry which reported an exacerbation rate of $55 \%[2,21-26]$. The relapse rate is $20 \%$ in our patient population compared with $44 \%$ in the Oklahoma registry [2]. This could be secondary to our limited number of patients who presented to our center.

Our study group had $36 \%$ of morbidly obese $\left(\mathrm{BMI}>40 \mathrm{~kg} / \mathrm{m}^{2}\right.$ ) patients who had significantly lower initial platelet count, high AST, and high initial troponin levels compared to the non-morbidly obese patients (Table 6). Our patients with obesity had high exacerbation (75\%) and relapse rates (50\%). There is a paucity of data on the relationship of TTP with obesity [27,28]. Therefore, this association needs to be further evaluated.

\begin{tabular}{|c|c|c|c|c|}
\hline Variable & Reference range & $B M \mid<40(n=7)$ & $B M I \geq 40(n=4)$ & p-Value \\
\hline Age, median (IQR) & & $44(33-75)$ & $41(35-48)$ & 0.71 \\
\hline \multicolumn{5}{|l|}{ Gender, n (\%) } \\
\hline Male & & $2(28.57)$ & $2(50.0)$ & \multirow{2}{*}{0.57} \\
\hline Female & & 5 (71.43) & $2(50.0)$ & \\
\hline Initial hemoglobin, median (IQR) & \multirow{2}{*}{$12.9-16.7 \mathrm{~g} / \mathrm{dl}$} & $8.7(6.5-11.2)$ & $9.1(8.1-10.65)$ & 0.71 \\
\hline Lowest hemoglobin, median (IQR) & & $6(5.3-7.7)$ & $6.4(5.85-7.65)$ & 0.57 \\
\hline Reticulocyte count, median (IQR) & $0.022-0.09010^{6} / \mathrm{ul}$ & $0.073(0.052-0.26)$ & $0.137(0.108-0.212)$ & 0.45 \\
\hline Initial platelet count, median (IQR) & \multirow{2}{*}{$153-32810^{3} / \mathrm{ul}$} & $22(14-36)$ & $11.5(9.5-15)$ & 0.07 \\
\hline Lowest platelet count, median (IQR) & & $9(7-12)$ & $9.5(8-10)$ & 0.77 \\
\hline LDH, median (IQR) & 313-618 IU/I & 2390 (1650-7270) & 4495 (4300-5965) & 0.25 \\
\hline ALT, median (IQR) & $21-72 \mathrm{U} / \mathrm{I}$ & $26(23-29)$ & $34.5(28-96.5)$ & 0.13 \\
\hline AST, median (IQR) & 17-59 U/I & $40(36-101)$ & $93(77-148)$ & 0.08 \\
\hline Initial troponin I, median (IQR) & \multirow{2}{*}{$0.000-0.034 \mathrm{ng} / \mathrm{ml}$} & $0.021(0.017-0.121)$ & $0.56(0.057-1.57)$ & 0.086 \\
\hline Peak troponin I, median (IQR) & & $0.064(0.017-5.42)$ & $1.57(0.169-2.08)$ & 0.73 \\
\hline
\end{tabular}

\section{TABLE 6: Comparison of laboratory data between morbidly obese and non-morbidly obese}

LDH: lactate dehydrogenase, ALT: alanine aminotransferase; AST: aspartate aminotransferase

Bold values are statistically significant ( $p$-value $<0.05)$.

The other subgroup of patients who had a high exacerbation rate were patients with a positive drug screen. Four of the five patients (80\%) with a history of drug abuse had TTP exacerbations in addition to a high incidence of AKI (66\%), as previously mentioned (Table 7). It is possible but difficult to prove that these drugs induce the autoimmune reaction of TTP or the causative for increased exacerbation in these patients. Further studies are needed to clarify the relation between drug use and TTP presentation and exacerbation. 
Baseline creatinine level $(\mathrm{mg} / \mathrm{dL})^{*}$

$\begin{array}{llcl}\text { Patient \#1 } & 0.9 & 0.95 & 1 \\ \text { Patient \#2 } & \text { N/A } & 1 & 0.7 \\ \text { Patient \#2 } & \text { N/A } & 1.28 & 1.09 \\ \text { Patient \#4 } & \text { N/A } & 1.5 & 0.8 \\ \text { Patient \#5 } & \text { N/A } & 1.88 & 1.1 \\ \text { Patient \#6 } & \text { N/A } & 4.7 & 3.3\end{array}$

TABLE 7: Creatinine levels in patients with positive drug screen

*Creatinine reference range: $0.66-1.25 \mathrm{mg} / \mathrm{dl}$

TTP is one of the few hematological emergencies that need to be addressed immediately with accurate diagnosis and initiation of therapy. Therapeutic plasma exchange (TPE), glucocorticoids, and rituximab are the most commonly used efficacious treatments available for TTP. Additional treatments and strategies are being investigated to more effectively treat and prevent exacerbation or relapse. Caplacizumab, a humanized antibody derived from nanoparticles, showed promising results in phase 2 (TITAN) and phase 3 (Hercules) studies and approved by Food and Drug Administration (FDA) on February 2019 for initial treatment of TTP along with plasma exchange and immunosuppressive therapy [29]. The mechanism of action is by inhibiting the interaction between uncleaved vWF multimers and platelets. Additionally, the use of recombinant ADAMTS13 is now offering treatment for people with congenital TTP and offers linear improvement in autoimmune TTP. Interestingly, N-acetylcysteine was found to disrupt the disulfide bonds in the vWF [30]. These new mechanisms of treatment offer great hope to patients diagnosed with TTP, yet further studies are needed to ascertain their efficacy and safety.

\section{Conclusions}

We observed a high incidence of acute kidney injury and high TTP exacerbation rates among patients with morbid obesity and a history of substance abuse. TTP is a rare disease and there is a paucity of data on the relationship of TTP with obesity and drug abuse. This relationship should be further investigated by doing retrospective and prospective studies with larger patient populations. In addition, patients diagnosed with TTP should be counseled for weight loss in case they have obesity (BMI> $30 \mathrm{~kg} / \mathrm{m}^{2}$ ) and also be screened and counseled for substance abuse. These interventions might decrease the chance of having TTP exacerbations.

\section{Additional Information \\ Disclosures}

Human subjects: Consent was obtained or waived by all participants in this study. Research and Clinical Projects Committee, The Brookdale University Hospital and Medical Center issued approval Protocol 20-15. RE: NEW PROTOCOL APPROVAL: Protocol 20-15., "Characteristics, disease course and management of patients diagnosed with TTP at Brookdale Hospital Medical Center" Protocol Version 1, February 15, 2020 Dear Dr. Ramachandran, Your request to initiate the new protocol listed above was reviewed on April 28, 2020, at the Ad Hoc meeting of the BHMC Research and Clinical Projects Committee (RCPC/IRB) and will be presented at the next IRB meeting on May 4, 2020. We are pleased to inform you that your request is approved by the unanimous vote of the HMC Research and Clinical Projects Committee (RCPC/IRB). Your request is approved from April 28, 2020, through April 26, 2021. Please note that an annual progress report for continuing review is due before April 26, 2021. A final progress report for closure is required should the project finish before that date. Please send your request for renewal at least one month in advance of the expiration date. If there are any changes to the protocol they must be submitted for IRB approval for prior implementation. Please refer to the Brookdale protocol number listed above in any future correspondence with the IRB office regarding this protocol. Sincerely, Signature Dr. Hal Chadow, MD, Chairman Research and Clinical Projects Committee (IRB). Animal subjects: All authors have confirmed that this study did not involve animal subjects or tissue. Conflicts of interest: In compliance with the ICMJE uniform disclosure form, all authors declare the following: Payment/services info: All authors have declared that no financial support was received from any organization for the submitted work. Financial relationships: All authors have declared that they have no financial relationships at present or within the previous three years with any organizations that might have an interest in the submitted work. Other relationships: All authors have declared that there are no other relationships or activities that could appear to have influenced the 


\section{References}

1. Moschcowitz E: An acute febrile pleiochromic anemia with hyaline thrombosis of the terminal arterioles and capillaries: an undescribed disease. Arch Intern Med. 1925, 36:89-93. 10.1001/archinte.1925.00120130092009

2. Page EE, Kremer Hovinga JA, Terrell DR, Vesely SK, George JN: Thrombotic thrombocytopenic purpura: diagnostic criteria, clinical features, and long-term outcomes from 1995 through 2015. Blood Adv. 2017, 1:590-600. 10.1182/bloodadvances.2017005124

3. Sadler JE, Moake JL, Miyata T, George JN: Recent advances in thrombotic thrombocytopenic purpura . Hematology Am Soc Hematol Educ Program. 2004, 407-423. 10.1182/asheducation-2004.1.407

4. Bendapudi PK, Hurwitz S, Fry A, et al.: Derivation and external validation of the PLASMIC score for rapid assessment of adults with thrombotic microangiopathies: a cohort study. Lancet Haematol. 2017, 4:157164. 10.1016/S2352-3026(17)30026-1

5. Joly BS, Coppo P, Veyradier A: Thrombotic thrombocytopenic purpura. Blood. 2017, 129:2836-2846. 10.1182/blood-2016-10-709857

6. George JN: Congenital thrombotic thrombocytopenic purpura: lessons for recognition and management of rare syndromes. Pediatr Blood Cancer. 2008, 50:947-948. 10.1002/pbc.21481

7. George JN, Nester CM: Syndromes of thrombotic microangiopathy. N Engl J Med. 2014, 371:654-666. 10.1056/NEJMra1312353

8. Shelat SG, Ai J, Zheng XL: Molecular biology of ADAMTS13 and diagnostic utility of ADAMTS13 proteolytic activity and inhibitor assays. Semin Thromb Hemost. 2005, 31:659-672. 10.1055/s-2005-925472

9. Mannucci PM, Parolari A, Canciani MT, Alemanni F, Camera M: Opposite changes of ADAMTS-13 and von Willebrand factor after cardiac surgery. J Thromb Haemost. 2005, 3:397-399. 10.1111/j.15387836.2005.01115.x

10. Mannucci PM, Canciani MT, Forza I, Lussana F, Lattuada A, Rossi E: Changes in health and disease of the metalloprotease that cleaves von Willebrand factor. Blood. 2001, 98:2730-2735. 10.1182/blood.v98.9.2730

11. George JN: Clinical insights from observations on ADAMTS13 deficiency in liver cirrhosis . Thromb Haemost. 2008, 99:987-988. 10.1160/TH08-05-0278

12. Uemura M, Fujimura Y, Matsumoto M, et al.: Comprehensive analysis of ADAMTS13 in patients with liver cirrhosis. Thromb Haemost. 2008, 99:1019-1029. 10.1160/TH08-01-0006

13. Nguyen TC, Liu A, Liu L, et al.: Acquired ADAMTS-13 deficiency in pediatric patients with severe sepsis . Haematologica. 2007, 92:121-124. 10.3324/haematol.10262

14. Blombery P, Scully M: Management of thrombotic thrombocytopenic purpura: current perspectives . J Blood Med. 2014, 5:15-23. 10.2147/JBM.S46458

15. Reese JA, Muthurajah DS, Hovinga JAK, Vesely SK, Terrell DR, George JN: Children and adults with thrombotic thrombocytopenic purpura associated with severe, acquired Adamts13 deficiency: comparison of incidence, demographic and clinical features. Pediatr Blood Cancer. 2013, 60:1676-1682. 10.1002/pbc. 24612

16. Bendapudi PK, Li A, Hamdan A, et al.: Impact of severe ADAMTS13 deficiency on clinical presentation and outcomes in patients with thrombotic microangiopathies: the experience of the Harvard TMA Research Collaborative. Br J Haematol. 2015, 171:836-844. 10.1111/bjh.13658

17. Mariotte E, Azoulay E, Galicier L, et al.: Epidemiology and pathophysiology of adulthood-onset thrombotic microangiopathy with severe ADAMTS13 deficiency (thrombotic thrombocytopenic purpura): a crosssectional analysis of the French national registry for thrombotic microangiopathy. Lancet Haematol. 2016, 3:237-245. 10.1016/S2352-3026(16)30018-7

18. Chiasakul T, Cuker A: Clinical and laboratory diagnosis of TTP: an integrated approach . Hematology Am Soc Hematol Educ Program. 2018, 2018:530-538. 10.1182/asheducation-2018.1.530

19. Matsumoto M, Bennett CL, Isonishi A, et al.: Acquired idiopathic ADAMTS13 activity deficient thrombotic thrombocytopenic purpura in a population from Japan. PLoS One. 2012, 7:e33029. 10.1371/journal.pone.0033029

20. Alwan F, Vendramin C, Vanhoorelbeke K, et al.: Presenting ADAMTS13 antibody and antigen levels predict prognosis in immune-mediated thrombotic thrombocytopenic purpura. Blood. 2017, 130:466-471. 10.1182/blood-2016-12-758656

21. Froissart A, Buffet M, Veyradier A, et al.: Efficacy and safety of first-line rituximab in severe, acquired thrombotic thrombocytopenic purpura with a suboptimal response to plasma exchange. Experience of the French thrombotic microangiopathies reference center. Crit Care Med. 2012, 40:104-111. 10.1097/CCM.0b013e31822e9d66

22. Page EE, Kremer Hovinga JA, Terrell DR, Vesely SK, George JN: Rituximab reduces risk for relapse in patients with thrombotic thrombocytopenic purpura. Blood. 2016, 127:3092-3094. 10.1182/blood-2016-03703827

23. de la Rubia J, Moscardó F, Gómez MJ, et al.: Efficacy and safety of rituximab in adult patients with idiopathic relapsing or refractory thrombotic thrombocytopenic purpura: results of a Spanish multicenter study. Transfus Apher Sci. 2010, 43:299-303. 10.1016/j.transci.2010.09.018

24. Ling HT, Field JJ, Blinder MA: Sustained response with rituximab in patients with thrombotic thrombocytopenic purpura: a report of 13 cases and review of the literature. Am J Hematol. 2009, 84:418421. 10.1002/ajh.21439

25. Jasti S, Coyle T, Gentile T, Rosales L, Poiesz B: Rituximab as an adjunct to plasma exchange in TTP: a report of 12 cases and review of literature. J Clin Apher. 2008, 23:151-156. 10.1002/jca.20172

26. Scully M, Cohen H, Cavenagh J, et al.: Remission in acute refractory and relapsing thrombotic thrombocytopenic purpura following rituximab is associated with a reduction in IgG antibodies to ADAMTS-13. Br J Haematol. 2007, 136:451-461. 10.1111/j.1365-2141.2006.06448.x

27. Nicol KK, Shelton BJ, Knovich MA, Owen J: Overweight individuals are at increased risk for thrombotic 


\section{Cureus}

thrombocytopenic purpura. Am J Hematol. 2003, 74:170-174. 10.1002/ajh.10418

28. Lombardi AM, Fabris R, Scarda A, et al.: Presence of anti-ADAMTS13 antibodies in obesity . Eur J Clin Invest. 2012, 42:1197-1204. 10.1111/j.1365-2362.2012.02710.x

29. Picod A, Coppo P: Developments in the use of plasma exchange and adjunctive therapies to treat immunemediated thrombotic thrombocytopenic purpura. Expert Rev Hematol. 2019, 12:461-471.

10.1080/17474086.2019.1619170

30. Chen J, Reheman A, Gushiken FC, et al.: N-acetylcysteine reduces the size and activity of von Willebrand factor in human plasma and mice. J Clin Invest. 2011, 121:593-603. 10.1172/JCI41062 